\title{
Sustainability Reporting Guidelines-Safety Issues for Oil Companies
}

\author{
Dr. Natalia Andreassen ${ }^{1}$
}

\begin{abstract}
There is a growing interest in sustainability reporting and its practices. Worldwide, this interest is especially urgent in hazardous industries where serious accidents have grave economic, social, and ecological impacts. The Gulf of Mexico oil spill triggered discussions of regulation and safety issues in oil companies which highlighted the complexity and risks of operations in the oil industry. Oil companies are called on to be transparent and accountable to the public regarding their corporate social responsibility; they are expected to disclose information regarding oil operations safety, including spill prevention and response plans. Existing sustainability reporting standards suggest a way for presenting sustainability performance information for stakeholders. Research literature focuses on industrial challenges and criticizes the current sustainability reporting initiatives for providing guidance of too generic a character. This article focuses on the question of how sustainability reporting represents oil operation safety issues. The study provides an overview of the current global sustainability reporting guidelines and analyzes how they recommend focusing on safety issues and response plans. The study discusses whether sustainability reporting frameworks are a useful platform for providing information about the oil companies' safety.
\end{abstract}

Key words: sustainable development, sustainability reporting guidelines, oil and gas companies, production safety

\section{Introduction}

Sustainability reporting introduces the concepts of sustainable development and corporate social responsibility (CSR) into the accounting field at the organizational level. Worldwide, the interest in the idea of sustainable development is especially urgent in hazardous industries with energy-, materials-, and workforce-intensive production having the potential of hugely negative economic, social, and ecological impacts. Among others, oil companies around the world have become pioneers and statistically dominant in CSR, environmental, or sustainability reporting to assure their stakeholders that their business develops in a sustainable way. However, major industrial accidents call into question whether stakeholder confidence is misplaced.

The 2010 oil spill at BP Deepwater Horizon drilling rig in the Gulf of Mexico remains the biggest petroleum industry production catastrophe. The accident spurred public concern over safety regulations for oil companies, fear about further oil exploration, and risks for wildlife and the environment, while highlighting shortcomings of existing financial and sustainability disclosure (Lewis, 2011; Boxell and Pfeifer, 2010; Gronewold, 2010). The quality of sustainability reports was questioned even as BP's sustainability reports had been highly ranked by the Global Reporting Initiative (GRI) (Lewis, 2011), 
the most prominent sustainability reporting framework today. It seems that sustainability reporting in that case failed as a useful instrument for an emergency prevention management system. One possible explanation for that could be limitations of the standards themselves. Therefore, an issue of concern that is worthy of attention is whether sustainability reporting frameworks are useful platforms for oil companies in their effort to provide information about production safety in their corporate sustainability reports.

This article explores how sustainability reporting guidelines represent oil operation safety issues. It starts with a review of the literature on the sustainability idea and sustainability reporting and then gives a substantial overview of global guidelines available to oil companies for sustainability reporting. The next sections suggest a research model and analysis of how the guidelines recommend focusing on safety issues and response plans.

\section{Literature}

The recent emergence of sustainability reporting has embedded the globalized concept of "sustainability development" into the management and accounting fields. The most often quoted definition of the "sustainable development" concept given by the World Commission on Environment and Development (WCED) is "development that meets the needs of the present without compromising the ability of future generations to meet their own needs" (Brundtland et al., 1987, p. 43). Sustainability reporting means corporate reporting on a company's performance in all respects and showing its capacity to endure.

The broad concept of sustainability reporting introduces a part of organizational accounting system that can be used as a managerial tool (Burritt and Schaltegger, 2010). "Just as conventional management and financial accounting have been a powerful tool in the management, planning, control, and accountability of the economic aspects of an organization, broader techniques of sustainability accounting and accountability have the potential to be powerful tools in the management, planning, control, and accountability of organizations for their social and environmental impacts" (Unerman et. al., 2007, p. $3)$. The concept has increasingly become integrated into the global managerial culture of every company wanting to be perceived as modern and legitimate (Gjølberg, 2009).

Nowadays, in many countries, there are concerns about essential distinctions in what companies report - why and how they report. Research literature illustrates the variety of practice with theoretical perspectives, which commonly refer to legitimacy and stakeholder theory (Owen, 2008; Unerman, 2007; Gray et al., 1995). Attempts to study different aspects of sustainability reporting practice employ stakeholder theory. It attempts to identify those affected by sustainability efforts, their perceptions of sustainability, and to link reporting strategies to particular stakeholder groups. The managerial mechanism of stakeholder theory assumes that organizations can influence the stakeholders who are believed to have an impact on the company. Literature recognizes the importance of developing approaches and tools to provide relevant information to stakeholders. However, the goal of capturing as many stakeholders' needs as possible can lead to a situation in which efforts and disclosures become overloaded with information and, therefore, not as valuable (Adams, 2010). Therefore, this 
perspective usually is closely interlinked with legitimacy theory which is used at most to explain motivations for corporate efforts in sustainability reporting (O'Dwyer, 2002; O’Donovan, 2002). The research highlights critical stakeholder groups and suggests that corporate reporting is being adapted to manage their legitimacy. The stronger the dependency on a stakeholder, the greater the probability that the organization will incorporate the stakeholder's demands into its operations (Mahadeo et al., 2011). Sustainability reporting is seen then as a possible legitimacy tool for influencing its critical stakeholders through various disclosure strategies (Tilling and Tilt, 2010; Adams, 2010; Deegan, 2007; O’Donovan, 2002). Another point in legitimacy theory is that corporate performance and the expectations of a larger social system can change over time, leading to changes in the legitimacy of the corporation. O'Donovan (2002) suggests illustrating this perspective by a situation in which some new information about a corporation's activities becomes known. The corporation is negatively associated with an issue/event, so its corporate image does not correspond to relevant societal expectations. Corporations seek to adapt sustainability reporting in order to communicate to their stakeholders and manage their legitimacy.

Current sustainability reporting standards suggest a way for presenting sustainability performance information for stakeholders. A number of global organizations have become standardizers that provide certain recommendations for non-financial reporting and describing management trends on sustainability. Guidelines and indicators can be applied in various types of companies, for disclosure of various information and to various stakeholders. They also can be used to ensure the quality of reporting, assurance, and auditing. Firstly, there are global recommendations which are applied generally by all companies worldwide. They recommend reporting principles, report content, and indicators for corporate performance. Particularly noteworthy are recommendations of the Sustainability Reporting Guidelines, issued by the Global Reporting Initiative (GRI). In research literature, GRI is considered to be one of the most dominant in efforts to standardize sustainability reporting (Owen, 2008). Secondly, there are sector- and industry-specific initiatives and ratings which are usually called "sector supplements." Their aim is to help companies manage and report sustainability impacts associated with the their industry. For instance, the global oil and gas industry association for environmental and social issues (IPIECA) is a global association representing the oil and gas industry on key global environmental and social issues. The IPIECA, the American Petroleum Institute (API), and the International Association of Oil and Gas Producers (OGP) have together released "Oil and Gas Industry Guidance on Voluntary Sustainability Reporting," principles that guide oil and gas companies in sustainability reporting. Also, multiple initiatives and rankings have been emerging at the national and regional levels.

Empirical studies in the context of oil and gas companies acknowledge that they tend to provide a greater volume of disclosures than other industries as a means of mitigating their negative impacts on the environment and society (Dong and Burritt, 2010). The oil industry has an important role in the global sustainability reporting discussion. The oil industry is among the leading industries in the issuance of social and environmental reports. The oil industry has been identified as an "environmentally sensitive" industry because of the significant and pervasive environmental impact caused by their central 
activities. Globally, oil companies are subject to more intensive environmental regulation, greater influence by stakeholder opinion (Wood and Ross, 2008), and are required to provide a higher percentage of verified environmental reports (Kolk et al., 2001) than companies working in many other industries. However, Dong and Burritt (2010) conclude that corporate disclosures by oil companies focus too much on common disclosures about employees and the environment: "relatively narrow focus ... undermines the credibility of social and environmental disclosures for decision making by investors because specific relevant information is not provided" (Dong and Burritt, 2010, p. 116).

Seeking to satisfy the needs of too many different stakeholders, companies may use various guidelines with indicators and recommendations. The problem with the great number of indicators and recommendations is that disclosed information may become irrelevant to the particular business and industrial setting, making it difficult for readers to read the reports. The research literature reflects that multiple standards may also result in confusion about a proper assessment system for sustainability reporting (Adams, 2010). Sustainability reporting might have peculiarities in different industries which demand the specific focus of corporate reporting guidelines.

\section{Background and Method}

The oil industry experiences a large number of production disasters that threaten sustainable development on the planet. The environmental and social damage resulting from accidents, inefficient natural resources usage, reduction of the energy supply, and energy supply interruption causes big losses to a country's development. Therefore, to avoid losses, it is necessary to address the issues of economic and financial stabilization, energy efficiency, and the ability to reduce production accidents and emergencies. As Burgherr and Hirschberg (2008) confirm, accidents in the energy sector have been recognized as one of the leading categories of manmade disasters. Production safety issues have also gained importance due to major and severe accidents taking place in the energy sector. Catastrophes like the Gulf of Mexico spill in 2010 challenge the relevancy of current corporate reporting systems in order in preventing and responding to accidents (Lewis, 2011; Boxell and Pfeifer, 2010; Gronewold, 2010).

A major accident affecting the global oil industry occurred on April 20, 2010, with the explosion of a platform owned by BP. This production accident resulted in the biggest unintentional offshore oil spill in the history of the petroleum industry (Telegraph, August 3, 2010). The oil spill in The Gulf of Mexico sent a challenge to the global oil industry. Causes of the catastrophe were discussed as well as the responsibilities of global oil companies, and also whether it had indeed been possible to prevent the catastrophe. "The Deepwater Horizon oil spill highlighted shortcomings of existing financial and sustainability disclosure standards and practice" (Lewis, 2011, p.197). The Gulf of Mexico accident raised concerns that reporting gives users a more transparent view of the company. The concerns were aimed at safety and risks associated with oil company operations and uncertainty as to whether a company takes production risks seriously in its attempts to prevent catastrophes and achieve sustainable growth. It seemed that 
corporate reporting had not responded sufficiently to external readers in providing information about production safety and risks.

After the oil spill a coalition of mostly institutional investors, Ceres, became interested in five main issues of safety which represented material risks for oil and gas companies. They demanded global oil and gas companies disclose their existing safeguards and plans of action in the event of another rig disaster and possible oil spill like the one experienced by BP and other companies in the Gulf of Mexico (Gronewold, 2010). Ceres is a national network of investors, environmental organizations, and other public interest groups working with companies and investors to address sustainability challenges. The investigation-led by more than 50 U.S. and global investors-focused on how global oil companies deal with production safety and whether corporate reports provide information about the companies' actions. The Ceres investigation requested global oil and gas companies to respond on five key topics: (1) company investments in spill prevention and response activity; (2) spill contingency plans for managing blowouts; (3) lessons learned from the BP oil spill, including more robust enforcement of offshore drilling in the Gulf and elsewhere; (4) possible actions to improve their safety contractor selection and oversight practices; and (5) governance systems for overseeing the management of offshore oil and gas operations (Fleming, 2010). The investors group highlights that oil companies globally are supposed to describe these issues openly through their corporate reports.

Spurred on by shortcomings in production safety disclosure revealed by the investigation carried out by Ceres after The Gulf of Mexico oil spill, this study uses the lens of production safety questions. The original questions mainly address deepwater drilling; however, it is important to manage risks no matter in what kind of drilling the companies are engaged-deepwater exploration, shallow-water offshore, or onshore. Therefore, the research codes are adapted to fit oil operations generally and are listed in the Table 1.

Table 1. "Production safety issues in corporate reporting"

(1) Company's investments in spill prevention and response activity:

- Investment in research and development with respect to safer drilling technologies;

- Investment in research and development with respect to technologies related to rig safety and accident prevention;

- Investment in research and development with respect to spill response technologies.

(2) Spill contingency plans:

- Details concerning a plan to manage blowouts. Steps the company is taking, including steps in partnership with its industry peers,

- to study and develop improved ways of containing and managing spills and blowouts.

- Frequency and approval of update of spill/disaster contingency plans.

- Current technology for cleaning up oil spills on the surface and

- plans to improve spill clean-up technology.

- Additional information for investors in evaluating policies, practices, and management systems for spill prevention and response.

(3) Specific spill response plans:

- Any lessons learned from the BP spill or other incidents causing a reassessment of its risk management, its well designs and drilling and completion procedures, or its disaster response plans.

- Actions with regard to health, safety and environment (HSE) performance. 


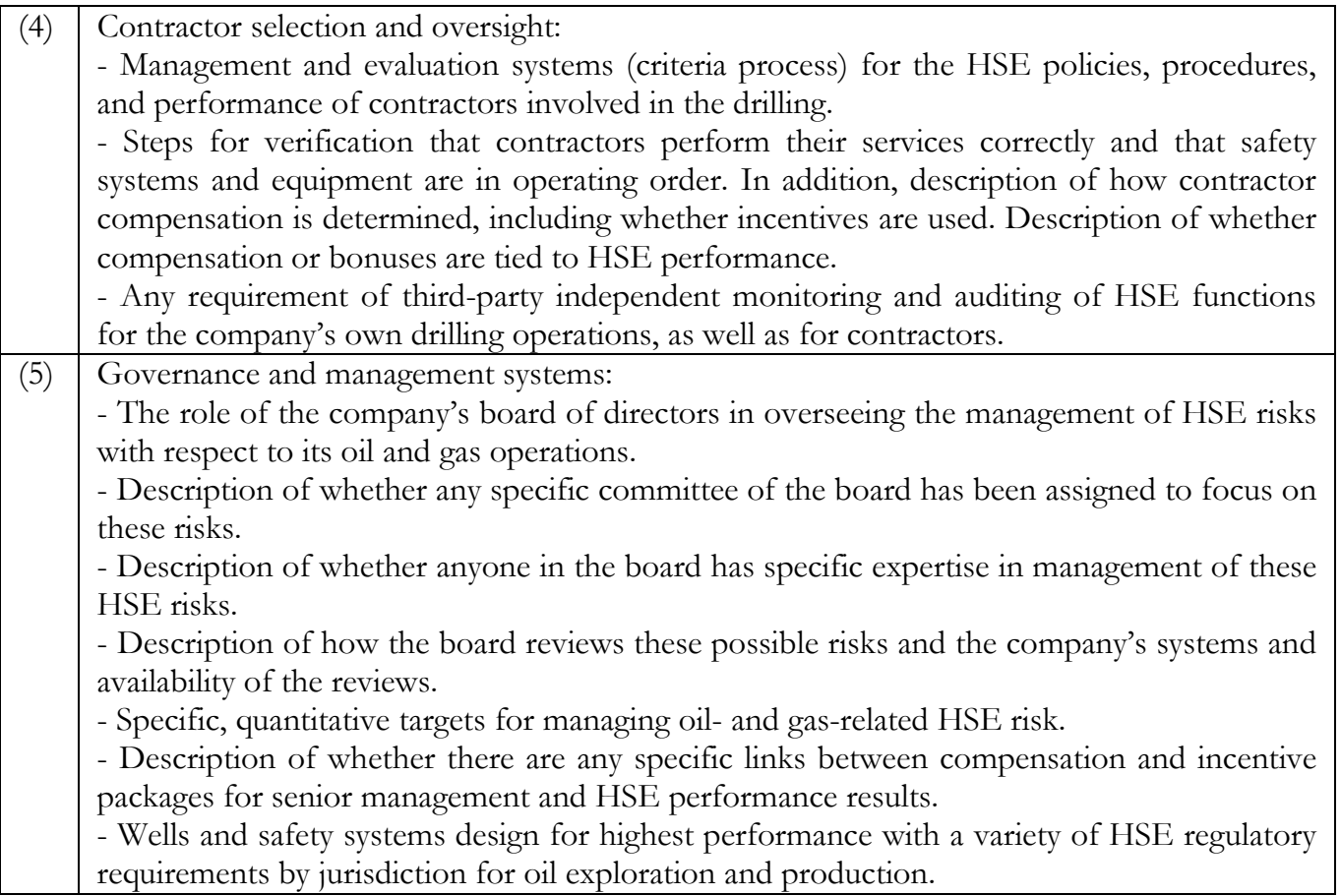

Qualitative summative content analysis (e.g., Hsieh and Shannon, 2005) is chosen as a research technique. This approach allows the buildup of the analysis around research codes identified in advance. The five model dimensions formed from the Ceres investors' investigation guided the analysis. Two most often used by oil companies' global sustainability reporting guidelines are chosen for this analysis. The Oil and Gas Industry Guidance on Voluntary Sustainability Reporting by IPIECA/API/OGP 2010 and the "GRI G3" guidelines issued by GRI are the most recently available versions of sustainability reporting standards after The Gulf of Mexico oil spill.

\section{Safety issues in the Oil and Gas Industry Guidance on Voluntary Sustainability Reporting by IPIECA/API/OGP}

IPIECA is the only global association involving both the upstream and downstream oil and gas industry on environmental and social issues. IPIECA's membership covers over half the world's oil production. IPIECA conducts a large number of its activities by working with other organizations and incorporating input from stakeholders. The organization launched "Oil and Gas Industry Guidance on Voluntary Sustainability Reporting" in cooperation with the American Petroleum Institute (API) and the International Association of Oil and Gas Producers (IOGP, formerly known as OGP). The second edition of "Oil and gas industry guidance on voluntary sustainability reporting” was issued in 2010 (IPIECA, 2010).

The guideline reports that oil and gas companies have been amongst the pioneers of sustainability reporting and have provided leading examples of good reporting practices. 
Therefore, guidance focuses on sharing good practice across the industry, encouraging companies to keep their stakeholders informed about their performance. The guidance consists of 146 pages and describes two types of assistance providing information on the process of reporting and the content of the report. The guideline suggests applying a robust environmental management system and performance indicators to demonstrate continuous improvement in reducing industrial impacts on the environment. The purpose is to "assess environmental impacts, mitigate risks of pollution or contamination through control technologies, continuously reduce the impact of emissions, discharges and waste streams, and respond effectively to accidents, such as marine spills" (IPIECA, 2010 , p. 54). The guideline also underlined that companies should select elements through which they can describe their responses to the challenges they face in different areas (IPIECA, 2010, p.54).

Regarding the safety questions, the recommendation to disclose a company's investments in spill prevention and response activity was not found in the IPIECA/API/OGP guidelines.

About spill prevention plans, the guidelines suggest two impacts and response actions for significant spills, emergency preparedness and response programs, plans, organizational structures and affiliations for an effective response to spills and other emergencies (indicator E8). It is necessary to study and develop ways of managing spills. The guidelines call for an explanation of actions, rather than naming or counting spills that have occurred, and suggests reporting on the causes of significant spills and the lessons learned from investigations.

Indicators (HS2), (HS3), (HS4) and (HS5) focus on occupational incidents and process and product safety. They recommend describing high-learning-value events, identifying risk-control barriers in past incidents and company experience with risk controls. They also recommend describing their knowledge of their specific sites and facilities to determine major risk scenarios and describe response actions for them, to manage product-related incidents and evaluate demands on the safety system

Regarding evaluation of relations with sub-contractors and third parties, there are recommendations in indicators (E8), (HS1), (HS3), (SE7) and (SE9). They require numerical measures, that is, separately reporting significant hydrocarbon spills from product transportation by third parties, to describe the extent to which contractors are involved in programs, and to discuss pre-qualification criteria for potential suppliers. Also, it is important to describe the policies, programs, and procedures the company has for promoting respect for human rights and core labor standards by suppliers, to monitor supplier adherence to contractual agreements related to human rights, and actions taken when the findings do not meet the company's expectations.

Recommendations regarding management systems with respect to environmental, health, and safety risks are found in the indicators (HS1), (HS4), and (HS5). The first two call for the company to describe its approach to managing workforce participation in health and safety dialogues and report specific activities that illustrate the application of the management approach and the product health, safety, and environment management system. The last one recommends that the company report on the effectiveness of management system execution and management committee and culture. 


\section{Safety issues in the G3 guidelines by GRI}

The Global Reporting Initiative (GRI) is a non-profit organization promoting economic, environmental and social sustainability. The mission of the GRI is to make sustainability reporting standard practice by providing guidance and support to organizations. The organization abides by the principle of multi-stakeholder engagement and provides all organizations with a comprehensive sustainability reporting framework. The GRI framework is widely used around the world. Its "G3" version was launched in 2006 and consists of 44 pages of the main Sustainability Reporting Guidelines followed by 4 pages of "GRI Application Levels" and 119 pages of "Indicator Protocols."

Regarding the safety questions, recommendations to disclose a company's investments relating to safer drilling technologies, technologies related to rig safety and accident prevention, or spill response technologies were not found. However, there is a generic call expressed by the indicator (EN30) to refer to total environmental protection expenditures and investments.

The concerns about spill prevention plans were found in the indicators (EN14), (EN19) and (EN23). They recommend reporting on strategies, current actions, and future plans for managing impacts on biodiversity, emissions of ozone-depleting substances by weight, and to disclose the total number and volume of significant spills.

The questions concerning actions to reassess specific response plans and risk management are found in the indicator (EN26) promoting initiatives to mitigate environmental impacts of products and services, and in (LA8) and (LA10) regarding education, training, prevention, and risk-control programs to assist workforce members. Also, there are (PR1) and (PR2), which concern the incidents of non-compliance with regulations and voluntary codes concerning health and safety impacts of products and services during their life cycle.

Relations with sub-contractors and third parties are found to be important in GRI. The indicator (EC6) recommends distinguishing policy, practices, and proportion of spending on locally-based suppliers at significant locations of operation.

The description of management systems specifically regarding oil operations safety are not required by the GRI indicators. However, it is stated that disclosures about the management approach should provide a brief overview under each indicator category to set the context for performance information (GRI, 2006, p.24). This means that any overview of risks and opportunities the company is currently facing should be described together with an appropriate management approach.

The findings are summarized in Figure 1. 


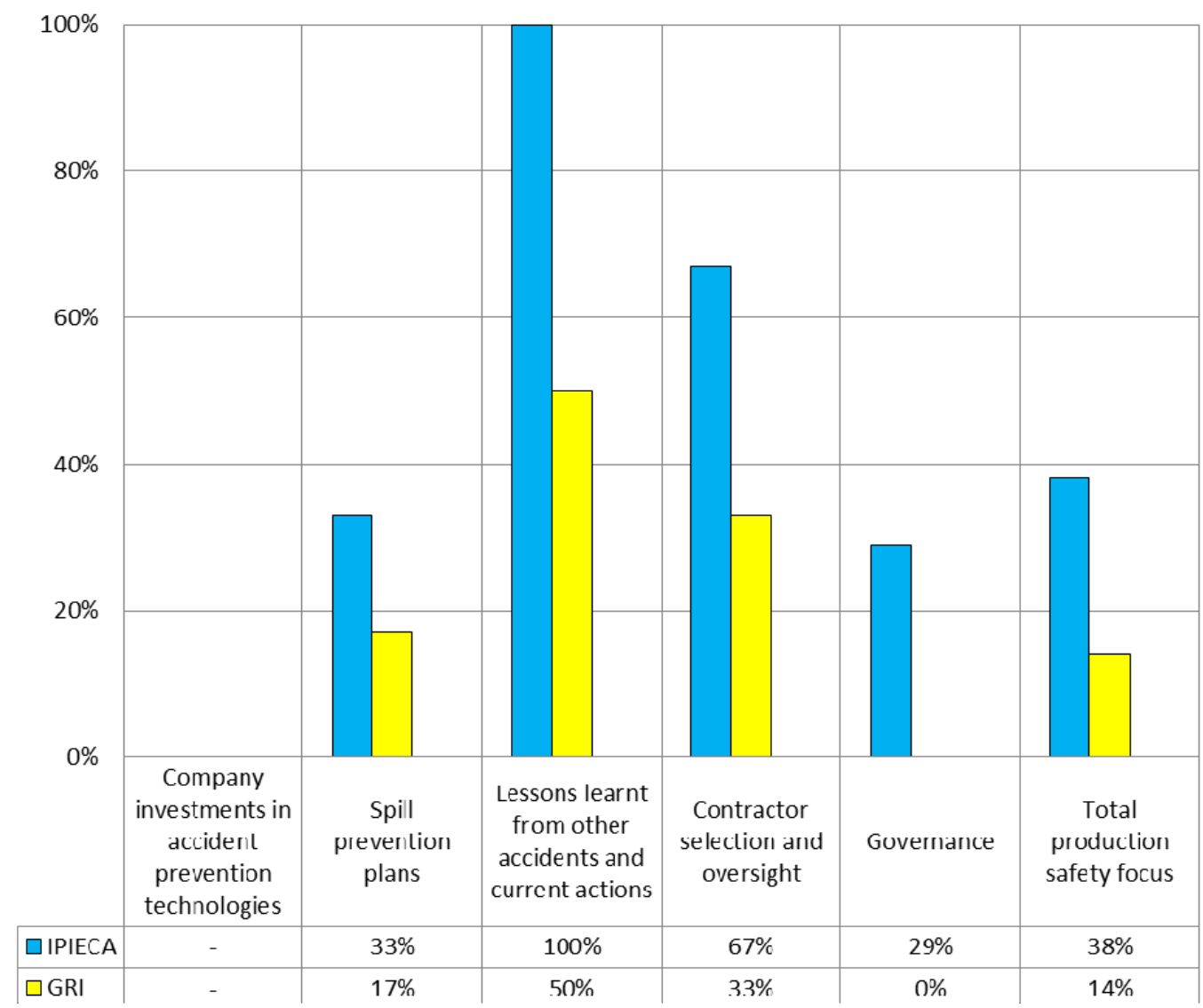

Figure 1. Safety issues in the Oil and Gas Industry Guidance on Voluntary Sustainability Reporting by IPIECA/API/OGP and in the G3 guidelines by GRI

\section{Discussion and Conclusion}

The main empirical findings reveal that the oil and gas sustainability reporting guidelines developed by IPIECA/API/OGP are more relevant in guiding production safety disclosure than the global sustainability reporting guidelines developed by GRI. The association IPIECA specializes in providing sustainability reporting recommendations to the oil and gas industry, so their guidelines focus on many safety issues relevant to oil companies' production processes. These guidelines encourage oil companies to include in their corporate reports those issues that are of special significance for the industry. The comprehensive global guidelines of GRI focus on keeping sustainability reporting mainstream. They naturally aim to capture mainstream business activity, without industry orientation, so the guidance does not include recommendations on specific production safety issues for oil companies.

The empirical analysis has focused on the production safety questions based on institutional investors' concerns. The coalition of institutional investors Ceres played an active part voicing their worries to global oil and gas companies after the accident in the 
Gulf of Mexico. Investors are important and influential stakeholders for oil and gas companies' decision-making. It is strategically important to disclose specific relevant information to enhance the credibility of the entire corporate report.

The analysis demonstrates that if an oil company intends to disclose production safety issues in sustainability reports it is more relevant to use IPIECA/API/OGP guidelines than the more dominant directions in sustainability reporting of the GRI guidelines. The more popular guidance is too generic and provides few recommendations about production safety issues. It seems rather challenging for oil companies to disclose production safety issues.

What is more, GRI is one of the most often used frameworks for assessment of sustainability reports. The quality of sustainability reports is usually judged by their compliance with GRI framework. To publish a highly ranked sustainability report, the report should be modelled according to the GRI framework. Disclosure of issues important for the industry does not influence the report's evaluations. This means that even a highly ranked assessment of a sustainability report with GRI criteria does not indicate how well the production safety issues are presented.

Accidents remind companies to use specific technologies and approaches for their production safety. Sustainability reporting has to include information on operations' safety, accident prevention, and emergency preparedness actions. For oil companies, it is more relevant to use industry-specific guidance both for sustainability reporting and for reporting assessments.

\section{References}

Adams, C.A. (2008). A commentary on: corporate social responsibility reporting and reputation risk management. Accounting, Auditing and Accountability Journal, 21(3), 365-370.

Adams, R. (2010). It's (already) beginning to look a bit like Christmas. Sustainability Accounting, Management and Policy Journal, 1(1), 85-88.

Boxell, J. and Pfeifer, S. (2010). BP spill leads to demand for more regulation, Financial Times, www.FT.com

Brundtland, G. and Khalid, M., Agnelli, S., Al-Athel, S.A., Chilzero, B., Fadika, L.M., et al. (1987). Our common future: The World Commission on Environment and Development, Oxford, Oxford University Press.

Burgherr, P. and Hirschberg, S. (2008). Severe accident risks in fossil energy chains: a comparative analysis, Energy, 33, 538-553.

Burritt, R.L. and Schaltegger, S. (2010). Sustainability accounting and reporting: fad or trend?, Accounting, Auditing and Accountability Journal, 23(7), 829-846.

Deegan, C. (2007). Organizational legitimacy as a motive for sustainability reporting, in Unerman, J. Bebbington, J. and O'Dwyer, B. (Eds.), Sustainability Accounting and Accountability, GB, Routledge.

Dong, S., Burritt, R. (2010). Cross-sectional benchmarking of social and environmental reporting practice in the Australian oil and gas industry. Sustainable Development, 18, 108-118.

Fleming, P. (2010). Investors Managing \$2.7 trillion press energy companies to better disclose spill prevention and response plans for deepwater wells worldwide, released 05.08.2010, accessed 01.09.2010, http://www.ceres.org/incr/news/oil-letters-080510.

Gjølberg, M. (2009). Measuring the immeasurable? Constructing an index of CSR practices and CSR performance in 20 countries. Scandinavian Journal of Management, 25, 10-22.

Global Reporting Initiative (GRI) (2006). Sustainability Reporting Guidelines, www.globalreporting.org.

Gray, R., Kouphy, R., and Lavers, S. (1995). Corporate social environmental reporting: A review of the literature and a longitudinal study of UK disclosure. Accounting, Auditing and Accountability Journal, $8(2), 47-77$. 
Gronewold, N. (2010, August 5). Investors ask oil, insurance groups to disclose safety plans, The New York Times. Retrieved from //http://www.nytimes.com/gwire/2010/08/05/05greenwire-investors-askoil-insurance-groups-to-disclose-67189.html

Hsieh, H.-F. and Shannon, S.E. (2005). Three approaches to qualitative content analysis. Qualitative Health Research, 15(9), No.9 1277-1288.

IPIECA (2010). Oil and gas industry guidance on voluntary sustainability reporting. IPIECA/API/OGP, $2^{\text {nd }}$ ed., http://www.ipieca.org/publication/oil-and-gas-industry-guidance-voluntary-sustainabilityreporting-2010-update.

Kolk, A., Walhain, S., and van de Wateringen, S. (2001). Environmental reporting by the Fortune Global 250: exploring the influence of nationality and sector. Business Strategy and the Environment, 10(1), 1528.

Lewis, S. (2011). Lessons on corporate "sustainability" disclosure from Deepwater Horizon. New Solutions, 21(2), 197-214.

Mahadeo, J.D., Oogarah-Hanuman, V., and Soobaroyen, T. (2011). Changes in social and environmental reporting practices in an emerging economy (2004-2007): Exploring the relevance of stakeholder and legitimacy theories. Accounting Forum, 35(3), 158-175.

O'Donovan, G. (2002). Environmental disclosures in annual report: Extending the applicability and predictive power of legitimacy theory. Accounting, Auditing and Accountability Journal, 15(3), 344-371.

O'Dwyer, B. (2002). Managerial perceptions of corporate social disclosure. The Irish story. Accounting, Auditing \& Accountability Journal, 15(3), pp.406-436.

Owen, D. (2008). Chronicles of wasted time?: A personal reflection on the current state of and future prospects for social and environmental accounting research. Accounting, Auditing and Accountability Journal, $21(2), 240-267$.

Telegraph (03 August, 2010). BP leak the world's worst accidental oil spill, www.telegraph.co.uk/finance/newsbysector/energy/oilandgas/7924009/, accessed 20 September, 2012.

Tilling, M.V. and Tilt, C.A. (2010) The edge of legitimacy: Voluntary social and environmental reporting in Rothmans' 1956-1999 annual reports. Accounting, Auditing and Accountability Journal, 23(1), 55-81.

Unerman, J. (2007). Stakeholder engagement and dialogue, in Unerman, J. Bebbington, J. and O'Dwyer, B. (Eds.), Sustainability Accounting and Accountability. GB, Routledge.

Unerman, J. Bebbington, J. and O'Dwyer, B. (Eds.) (2007). Sustainability Accounting and Accountability. GB, Routledge.

Wood, D. and Ross, D. G. (2006). Environmental social controls and capital investments: Australian Evidence. Accounting and Finance, 46(4), 677-695. 